\title{
O fim do conhecimento e o desvario político
}

\author{
José Leon Crochík ${ }^{\mathrm{a}}$ \\ Pedro Fernando da Silva ${ }^{a}$ \\ Cintia Copit Frellera* \\ Maria Lívia Tourinho Moretto ${ }^{b}$ \\ a Universidade de São Paulo, Instituto de Psicologia, Departamento de Psicologia da Aprendizagem, do \\ Desenvolvimento e da Personalidade. São Paulo, SP, Brasil \\ ${ }^{b}$ Universidade de São Paulo, Instituto de Psicologia, Departamento de Psicologia Clínica. São Paulo, SP, Brasil
}

O trabalho de editoração deste número é dedicado à memória da Professora Emérita Ecléa Bosi, cujas causas defendidas contribuem de forma substancial para uma humanidade mais justa e para uma vida mais digna.

Na sociedade de hoje, em que tudo deve seguir padrões muito bem delimitados, a ciência e a técnica têm se conformado a ser modos de procedimento para tentar verificar a regularidade do movimento dos objetos que estuda e a eficácia dos conhecimentos que aplica. Sua finalidade é esquecida ou ignorada e, em vez de perguntas como "por quê?" e "para quê?", só restam questões sobre o "como".

Se o método é próprio ao sujeito que, por meio dele, tenta conhecer o objeto, sua independência desse método possibilita que o conhecimento seja reduzido a esse sujeito a partir da regularidade que projeta sobre o mundo. Ponto fixo que o conhecimento partilha com a paranoia; não por acaso, Horkheimer e Adorno (1947/1985) argumentam que a paranoia é a sombra do conhecimento. Nada pode deixar de ser atingido pelo método, mas o que se atinge não é o objeto, e sim o que é necessário para torná-lo próprio ao sujeito, sua propriedade.

O cultivo da ciência positivista como única forma legítima de conhecimento implica na supervalorização do método, que a rigor é uma intenção cognoscitiva do sujeito diante da realidade a conhecer, em detrimento dos objetos efetivos, que são irredutíveis aos instrumentos criados para conhecê-los. A primazia concedida pelo positivismo ao método se destaca como uma das principais marcas do cientificismo contemporâneo e confere a essa invenção do sujeito o status de processo único e necessário do conhecimento. Com isso, a despeito da pretensão de negar o sujeito, na ciência positivista tal como na paranoia, a percepção é rigidamente dirigida por categorias prefixadas pelo sujeito, de modo que "O elemento subjetivo é cegamente introduzido por ela na aparente auto-doação do objeto" (Horkheimer \& Adorno, 1947/1985, p. 181).

A constituição desse método, no entanto, é histórica e depende da experiência que, ao longo do tempo, contrapõe a cultura à natureza para que possa cada vez mais ser distinta dessa última; assim, o método científico que expressa a possibilidade do sujeito, da subjetividade,

* Endereço para correspondência: revpsicousp@gmail.com como pensamento, como conhecimento, tem sua origem em condições objetivas que o necessitam.

$\mathrm{Na}$ sociedade atualmente caracterizada pela reestruturação produtiva, a organização dos centros de produção do conhecimento também está mediada por condições objetivas pouco favoráveis ao livre pensamento. A produção do conhecimento não ocorre a despeito do enfraquecimento objetivo dos indivíduos, mas mediada por ela. Isso significa que a disposição necessária à autorreflexão dos sujeitos no processo do conhecer, a consciência de si mesmo - que, segundo Horkheimer e Adorno, permitiria ao trabalho do pensamento "escapar a esse poder alucinatório" (1947/1985, p. 181) - está prejudicada: pesquisadores e beneficiários em geral do conhecimento científico encontram-se também intimamente determinados pelas condições de produção da ciência; não apenas a sua vida intelectual, mas também sua existência material é ameaçada, comprometendo tanto o modo de produção quanto a finalidade do conhecimento.

A reflexão sobre a constituição do método indica que sua neutralidade é inexistente, pois atende aos interesses humanos, sobretudo de quem socialmente tem mais poder. Isso não implica, todavia, que o pesquisador não deve ter algum afastamento do que estuda para sua melhor compreensão, mas que o fim da ciência e da técnica são socialmente determinados. Nesse sentido, Horkheimer e Adorno (1947/1985) argumentam que a técnica é tão democrática quanto a sociedade na qual se desenvolve.

Para Tragtenberg (1982) - que em terras tupiniquins se indignou com a promíscua relação da universidade brasileira com o poder econômico estabelecido -, as estruturas de produção do conhecimento, as instituições de ensino e pesquisa, que experimentaram a "passagem da universidade pretensamente humanística e mandarinesca à universidade tecnocrática" (p. 12), sucumbiram a uma organização das estruturas de ensino em que a ênfase nos técnicos levou-os a serem assumidos como fins, suplantando-se, com isso, os fins formativos. Sem deixar de considerar a dimensão institucional, por meio da qual professores, pesquisadores e alunos são controlados por critérios de avaliação coerentes com o sistema social opressivo, dirigiu sua crítica também ao nível de responsabilidade que cada um desses agentes apresenta em relação às finalidades sociais do conhecimento: 
O problema significativo a ser colocado é o nível de responsabilidade social dos professores e pesquisadores universitários. A não preocupação com as finalidades sociais do conhecimento produzido se constitui em fator de "delinquência acadêmica" ou da "traição do intelectual". (Tragtenberg, 1982, p. 14)

Se Marx (1984) pôde opor as forças produtivas das quais a ciência e a técnica são parte - às relações de produção, defendendo que as primeiras iriam "arrebentar" o acorrentamento próprio das últimas, Adorno (1968/2004) defende que a previsão do materialista histórico se inverteu, e que as forças produtivas passaram a reproduzir as relações de produção. A ilusão da neutralidade social da ciência e da tecnologia permite uma nova forma de acorrentamento.

Em consonância com a análise de Horkheimer e Adorno (1947/1985) quanto ao caráter contraditório da técnica, Marcuse (1941/1999), que ponderou que ela pode "promover tanto o autoritarismo quanto a liberdade, tanto escassez quanto a abundância, tanto o aumento quanto a abolição do trabalho árduo" (p. 74), centrou sua crítica no fato de que tanto a técnica quanto os indivíduos que a produzem são fatores da tecnologia, compreendida por ele como modo de produção:

A tecnologia, como modo de produção, como a totalidade dos instrumentos, dispositivos e invenções que caracterizam a era da máquina, é assim, ao mesmo tempo, uma forma de organizar e perpetuar (ou modificar) as relações sociais, uma manifestação do pensamento e dos padrões de comportamento dominantes, um instrumento de controle e de dominação. (Marcuse, 1941/1999, p. 73)

Quando a racionalidade da técnica - ou, como prefere Habermas (1968/1983), a esfera do agir racional com respeito a fins - invade a esfera da interação social, a lógica dessa última se restringe à da primeira, e a política, assim como diversas outras ações humanas, passam a se reduzir a uma forma de entendimento que as expropria do que lhes é próprio. $\mathrm{Na}$ área da política, as decisões que deveriam ser sociais passam a ser expressas como atinentes à administração do que já existe. Nesse sentido, a ciência e a técnica se tornam conservadoras.

Nas sociedades capitalistas tardias como a nossa, calcadas na administração precisa de quase todos os âmbitos da existência, predomina a instrumentalização do conhecimento científico em função do incremento da produção e do aumento do controle sobre as forças que poderiam representar oposição à ordem estabelecida. Nesse contexto, a pesquisa acadêmica é fomentada em maior ou menor medida de acordo com o reconhecimento de seu potencial para atender a demandas específicas, sobretudo da parcela abastada da sociedade. Esse atrelamento tácito da produção científica aos interesses políticos dominantes pode, a depender do modo predominante de organização da produção, suportar diferentes formas de apoio e de finalidade da produção científica. O tipo de delinquência acadêmica criticada por Tragtenberg (1982) na década de 1980, por exemplo, refere-se a um modo de financiamento das instituições de ensino e pesquisa que atualmente está em franco declínio. Com a crescente instrumentalização do Estado em função dos interesses econômicos hegemônicos, continuidade de tendências totalitárias, fortalece-se também o entendimento de que o financiamento da pesquisa científica deve ser assegurado não pelo Estado, que seria responsável por garantir sua finalidade pública, mas sim pelo setor privado, encurtando a distancia entre ambas as esferas. Se patrocinada pelo Estado, que representava os interesses conflitantes da sociedade contraditória, a ciência já se tornara suscetível à mediação dos interesses econômicos, agora, patrocinada diretamente pelo setor privado, não terá mais como resistir à sua interira subordinação a esses interesses. Portanto, a influência que exerce sobre as demais esferas da vida deve ser observada com preocupação.

Não obstante sua subordinação aos interesses econômicos capitalistas, o conhecimento já experimentou outras formas de vinculação com a esfera do poder, inclusive não econômicas. Como explicitaram Horkheimer e Adorno (1947/1985), a dominação capitalista é somente a forma contemporânea da dominação que acompanha o esclarecimento desde tempos imemoriais. O controle sobre o psiquismo e sobre o comportamento humanos é um desses efeitos que a ciência e a técnica pretensamente neutras produzem. A afirmação cega da racionalidade tecnológica que assegura a dominação parece ser, ela mesma, irracional.

O entendimento do que não segue a razão pelas leis da racionalidade a que se reduziu sacrifica a própria natureza do que é humano. Como ilustram Horkheimer e Adorno (1947/1985, p. 37):

Até mesmo aquilo que não se deixa compreender, a indissolubilidade e a irracionalidade, é cercado por teoremas matemáticos. Através da identificação antecipatória do mundo totalmente matematizado com a verdade, o esclarecimento acredita estar a salvo do retorno do mítico.

Tal crítica que já se dirige à psicanálise que reduz o inconsciente a componentes lógicos, para ser apreendido da mesma forma que os objetos inanimados ou os que nos servem de alimentação, é delimitada pelos próprios autores ao indicarem que o problema não é propriamente da matemática e da lógica - importantes para autoconservação humana -, mas o querer conhecer tudo de antemão; é a necessidade de controle que está presente, o que torna a ciência não só conservadora, como também meio de poder, isto é, política. O conhecimento como forma de controle torna-se poder político. É nesse sentido que podemos refletir sobre o fim atual, o objetivo, da ciência e da técnica existentes. 
Se, como manifestado no parágrafo anterior, mesmo a psicanálise que se propõe como outra forma de conhecimento continua a visar o poder, partilha a mesma tendência da ciência e da técnica e, por isso, é tão conservadora e representante do controle sobre a vontade alheia quanto essas.

A própria ciência, contudo, mesmo sem a autorreflexão necessária para reconhecer sua determinação social e assim servir à humanidade e não somente aos que detêm o poder admite que não pode conhecer tudo. O próprio Freud (1930/1986) admitiu que era necessária a especulação para preencher o que a ciência ainda não tinha conhecimento, e não deixa de mencionar que sua teoria de pulsões é da ordem do mito.

Se a tudo é aplicado o pensamento matemático, o que não se consegue compreender é passível de superstição, de pensamento mágico, que, por vezes, tenta se passar por ciência, como a tentativa de saber o destino por meio da astrologia, da numerologia etc. A política que não se deixa reduzir às ciências sociais, ao não poder ser autorrefletida segundo as condições objetivas que a determinam, é reduzida a características pessoais de políticos ou a conflitos de grupos de interesses, sem que nenhuma estrutura social seja perceptível na sua constituição. A respeito da consequência advinda do cerceamento do pensamento não redutível à matemática, alegam Horkheimer e Adorno (1947/1985, p. 13):

$\mathrm{Na}$ crença de que ficaria excessivamente susceptível à charlatanice e à superstição, se não se restringisse à constatação de fatos e ao cálculo de probabilidades, o espírito conhecedor prepara um chão suficientemente ressecado para acolher com avidez a charlatanice e a superstição. Assim como a proibição sempre abriu as portas para um produto mais tóxico ainda, assim também o cerceamento da imaginação teórica preparou o caminho para o desvario político.

Se as ciências humanas e a técnica só têm se preocupado com o seguimento de procedimentos consagrados nas ciências da natureza, tornando essa inteligível à luz da lógica da matemática, e não aplica a razão para pensar sua finalidade, o mesmo parece ocorrer com a política, que não tem seguido, ao que parece, nenhum princípio de sua lógica inerente, nem mesmo a aparência democrática.

Distanciando-se do campo do debate público, a política praticada nas instituições da democracia formal tem se convertido cada vez mais na habilidade de manipular pessoas e situações em prol de interesses privados, muitos dos quais absolutamente escusos. A racionalidade desenvolvida em consonância com a estruturação da sociedade capitalista, que expressa o espírito interessado da dominação de classes, permeia também o conjunto das organizações sociais e orienta a administração da produção e da aplicação do conhecimento científico. A política que nega a possibilidade própria do debate político orienta a racionalidade irracional que determina os fins da produção científica.

Horkheimer (1932/1990) já havia notado, no início do século passado, que a crise da ciência expressava a crise da sociedade e que a riqueza de recursos destinados à produção científica não tinha como correlato a superação da miséria, pois, conforme constatou, a ciência não se orientava por suas próprias tendências, e sim por determinantes externos, pelas "necessidades sociais da vida":

Atualmente, o laboratório de ciências apresenta um retrato da economia contraditória. Esta é altamente monopolística e mundialmente desorganizada e caótica, mais rica do que nunca e, ainda assim, incapaz de remediar a miséria. (Horkheimer, 1932/1990, p. 11)

Embora o montante de recursos públicos outrora empregados à produção científica com vistas à promoção de tecnologias convenientes à reprodução do capital, atualmente, esteja sofrendo cortes progressivos, a transferência da responsabilidade do financiamento da pesquisa para órgãos privados mantém, de forma mais desvelada, o investimento de grande fluxo de recursos financeiros nas áreas que podem se reverter imediatamente em tecnologias que favoreçam a manutenção do sistema social injusto e a reprodução desenfreada do capital historicamente concentrado nas mãos de pouquíssimos integrantes da alta burguesia. Alinhada à ensandecida política da dominação, a ciência que a alimenta e justifica parte de seus procedimentos, e tem, igualmente, seus fins por ela definida, define também os termos formais da administração da realidade.

A democracia formal tem regras que obscurecem as contradições que a impedem de se realizar plenamente, e isso parece ter eclipsado sua finalidade: a mediação dos interesses sociais existentes, ainda que, em uma sociedade de interesses contraditórios, essa mediação encontre limites intransponíveis. Mas até a possibilidade de manter essa aparência parece se perder. Isso é notável dentro e fora da academia científica.

Dentro, porque pesquisadores que detêm o poder dizem ser legítimo concorrer ao mesmo que os que não têm esse poder, ignorando conflitos de interesse; outros tentam manter um equilíbrio fictício entre os interesses, pregando a divisão igual de participação de grupos organizados diversos, como se esses fossem semelhantes em sua atuação. Fora da academia, quando em um momento de crise financeira quem governa faz cortes de financiamentos proporcionalmente equivalentes, atendendo a uma justiça formal que é injusta com a finalidade política do bem geral da população.

Em relação a essa última questão, a pergunta pelo fim do conhecimento é vital. O corte de verbas para as universidades públicas, as dificuldades orçamentárias das agências de fomento à pesquisa, mostram o desvario político da injustiça do corte generalizado. Interromper uma pesquisa, uma formação profissional, o desenvolvimento 
de um mestrado, de um doutorado, não é similar por suas consequências à interrupção da construção de uma obra da engenharia, por mais que essa também traga transtornos.

A agenda governamental atualmente em voga expressa a priorização cínica dos interesses econômicos dos grandes industriais e do capital financeiro em detrimento de medidas que poderiam assegurar as condições mínimas de vida para a grande maioria da população, ainda privada do acesso à formação e à ciência.

Se nos últimos tempos a verba destinada à ciência e à tecnologia aumentou substancialmente, ainda é uma fração mínima do PIB brasileiro. No momento, contudo, algo pior ameaça a academia e a produção do conhecimento: a "visão" curta de quem usa uma tesoura para cortar indiferentemente o que estiver a sua frente. Essa cegueira é expressão do desvario político enunciado já no título deste editorial; desvario esse, conforme foi indicado, também de uma ciência pretensamente descomprometida, mas cujo compromisso não pode ser imediato, fazendo a ciência perder sua especificidade que pode servir à ilustração: a ciência engajada não é menos cega do que a que se pretende neutra; uma e outra perderam o seu fim.

Se a aplicação de uma racionalidade técnicoadministrativa consonante com os interesses do capital aos campos da formação e da pesquisa implica na redução da responsabilidade social, expressada atualmente pela menor responsabilidade do Estado pela educação, pela cultura e pela ciência, de outro lado, o possível aumento de recursos financeiros por meio de parcerias entre o Estado e empresas privadas pode significar uma ainda maior alienação da ciência em relação a questões sociais urgentes. Pode representar a continuidade de uma riqueza perversa, absolutamente indiferente à miséria e aos sofrimentos gerais.
Se a produção do conhecimento e a formação de profissionais universitários têm seus limites e contradições - assim como, nesta sociedade, o tem qualquer atividade humana -, o estrangulamento financeiro impingido a instituições públicas da educação e da ciência, únicas com potencial, ainda que contraditório, para a distribuição justa do acesso à produção e à distribuição do conhecimento, não só as inviabiliza momentaneamente, mas interrompe movimentos que talvez não sejam recuperados e torne o país mais dependente ainda de conhecimentos oriundos de outros lugares, sustando nosso rumo, já demorado, a uma autonomia razoável a ser alcançada nesse campo.

A delinquência acadêmica já revelava o sistema de privilégios representado pelo processo de seleção injusta para as principais instituições públicas do país, incitando a desconfiança popular em relação às mais conceituadas universidades, inclusive as públicas. A forma atual do desvario político, que orienta a atual política de ciência e tecnologia, parece cumprir um arremate nessa situação, pois acentua a injustiça que permeia o acesso ao conhecimento e, além disso, retira o potencial de democratização presente no setor público, cada vez mais estrangulado pela falta de recursos financeiros. Se a produção do conhecimento, sobretudo do que é redutível à tecnologia requerida pela produção burguesa, passa a ser custeada diretamente pelo capital, isso libera o Estado da obrigação de financiá-la. Como consequência, as formas de conhecimento resistentes a essa redução passam a ser mais facilmente descartadas como gasto excessivo, como luxo de intelectuais formados, contraditoriamente, por um sistema que nunca cumpriu a promessa de se tornar democrático.

\section{Referências}

Adorno, T. W. (2004). Capitalismo tardío o sociedad industrial? In T. Adorno, Escritos sociológicos I (Obra completa 8, pp. 330-344). Madrid, España: Akal. (Trabalho original publicado em 1968)

Freud, S. (1986). El malestar en la cultura. In N. A. Braustein (Org.), \& J. L. Etcheverry (Trad.), A medio siglo de " $E l$ malestar en la cultura” de Sigmund Freud (pp. 22-116). Ciudad de México, México: Siglo Veintiuno. (Trabalho original publicado em 1930)

Habermas, J. (1983). Técnica e ciência enquanto ideologia. In Textos escolhidos / Walter Benjamin, Max Horkheimer, Theodor W. Adorno, Jürgen Habermas. Trad. Zélyko Loparic e Andrea M.A. de Campos Loparic. São Paulo: Abril Cultural. (Trabalho original publicado em 1968)
Horkheimer, M. (1990). Observações sobre ciência e crise. In M. Horkheimer, Teoria Crítica I (pp. 7-12.). São Paulo: Perspectiva. (Trabalho original publicado em 1932)

Horkheimer, M., \& Adorno, T. W. (1985). Dialética do esclarecimento: fragmentos filosóficos. Rio de Janeiro, RJ: Zahar. (Trabalho original publicado em 1947)

Marcuse, H. (1999). Algumas implicações sociais da tecnologia moderna. In H. Marcuse, Tecnologia, guerra e fascismo (pp. 71-104). São Paulo: Unesp. (Trabalho original publicado em 1941)

Marx, K. (1984). O capital: crítica da economia política (Livro 1, Vol. 1). São Paulo: Difel.

Tragtenberg, M. (1982). A delinquência acadêmica. In M. Tragtenberg, Sobre educação, política e sindicalismo (pp. 11-16). São Paulo: Cortez. 